\title{
Hortus Amoenus: Fasti, Flora y una poética espacial
}

\author{
Maricel Radiminski \\ Universidad de Buenos Aires. Facultad de Filosofía y Letras \\ - CONICET, Argentina \\ maricelradiminski@gmail.com
}

\section{RESUMEN:}

Estudiaremos el tratamiento de espacios como el locus amoenus y los jardines en el episodio dedicado a Flora en los Fast $i$ ovidianos (V.183-378) a fin de determinar los alcances metapoéticos de estos escenarios.

Palabras Clave: Ovidio, Fasti , Locus amoenus, Jardín.

\section{ABstract:}

I will study the treatment of spaces like the locus amoenus and the gardens in the episode dedicated to Flora in the Ovidian Fast $i$ (V.183-378). I aim to point out the metapoetic reaches of these literary scenes.

KEYWORDS: Ovid, Fasti, Flora, Locus amoenus, Garden.

Como es sabido, la inclusión y caracterización de determinados espacios en la literatura latina suele tener implicancias metaliterarias. Es el caso del locus amoenus y de los jardines, cuya presencia no solo sirve de marco para el desarrollo de escenas de distinta índole sino que también da cuenta de la artificiosidad y las características de los textos desde un punto de vista poético. A su vez, tanto el jardín como el locus amoenus se vinculan con las flores y demás elementos de la vegetación concentrados en los dominios de la diosa Flora, protagonista de Ov., Fast., V.183-378 ${ }^{1}$. En esta línea, nos proponemos estudiar la función de dichos sitios en el pasaje consagrado a esta deidad, ya que consideramos que se trata de ítems relevantes en la configuración literaria de su historia. El episodio en cuestión muestra cómo Flora protagoniza diferentes transformaciones que, atravesadas por tales escenarios, le permiten hacerse de su estatus divino y, asimismo, hacen partícipe de dichas transformaciones al mismo poema, cuyo soporte elegíaco, su asunto solemne y su tono didáctico lo construyen como un híbrido literario.

\section{FLORA Y FASTI}

En principio, según señalara Newlands ${ }^{2}$, vale recordar que las mismas características de Flora hacen de ella una diosa representante de la ambivalencia de Fasti: si bien se trata de una antigua divinidad itálica cuyos dominios (las flores y demás elementos agrestes ${ }^{3}$ ) no parecerían ubicarla dentro de las más importantes, los Floralia ocupaban un lugar relevante en la agenda religiosa, pues se realizaban desde el 28 de abril hasta el 3 de mayo y su culto formaba parte de una serie de celebraciones que apelaban a la prosperidad de las cosechas. Lo mismo cabe para el templo de Flora, que fue restaurado por Augusto y terminado por Tiberio, lo cual deja ver que, a pesar de tratarse de una divinidad menor, hubo preocupación por parte de los miembros de la gens gobernante por el culto a la diosa ${ }^{4}$. A su vez, dado que sus festividades se distribuían durante dos meses, esta deidad se ubica en los confinia (V.187) y maca así su posición liminal. De hecho, si bien Ovidio relega su participación al cuarto libro de Fasti en pos de la conmemoración del culto de Vesta al interior del Palatino (IV.943-950 $)^{5}$, más adelante le ofrece plena dedicación en el libro siguiente, hecho que configura uno y otro 
mes como 'espacios' de pertenencia de Flora y muestra, también, completa atención hacia ella. De este modo, Flora se aleja de las divinidades principales y parece constituirse como una deidad de bajo orden, rango que podría compartir, en términos metaliterarios, con un texto elegíaco, pero cuyo material resulta, al igual que el asunto del calendario, efectivamente atendible.

Esta misma ambivalencia funciona dentro del texto a partir de la figura de Flora y su potencial creador. En efecto, en Fasti se apela a Flora como una deidad iocosa (IV.946; V.183; 5.332) y de numen non severum (V.333) pero que a través de las flores es capaz de dar vida a valiosas producciones (optima auctor, V.193). A su vez, el diálogo que la diosa mantiene con el enunciador, donde este pregunta a la deidad por los pormenores de su culto y sus festividades y ella responde explayadamente, parece recuperar elementos propios de la poesía didáctica ${ }^{6}$, género del que también participa el calendario ovidiano. En el episodio que nos ocupa, el intercambio entre ambos personajes presenta a Flora en el rol de magistra (ipsa doce tua sis, V.191) al mismo tiempo que su interlocutor tiende a constituirse como discipulus ('ius tibi discendi, siqua requiris' ait, 276). De esto se desprende que aquello que Flora produce es susceptible de ser enseñado, tal es así que, a través de la técnica de la entrevista ${ }^{7}$, ella misma instruirá al enunciador acerca de los pormenores que hacen a la historia de sí misma. Durante este proceso, la diosa también mostrará a su interlocutor un nuevo modo de hacer literatura ${ }^{8}$, que combina la elegía con los asuntos maiores y el discurso didáctico, en el que ciertas categorías espaciales se tornan relevantes. En efecto, las 'obras' de Flora toman forma a partir de la manipulación que ella ejerce sobre distintos elementos naturales tales como las flores, que se involucran con los espacios que las incluyen, propiciando así la participación de dichos escenarios. Aquí es donde toman protagonismo el jardín ( hortus) y el locus amoenus, en los que nos detendremos a continuación.

\section{HoRTUS Y LOCUS AMOENUS: PAISAJES 'ARTIFICIALES'}

Dado que Flora es la diosa consagrada a las flores y demás elementos del mundo vegetal, resulta sencillo asociar su figura con diversos espacios naturales. Puesto que el texto vincula la potestad de Flora con los jardines y, en esta descripción, incluye un locus amoenus, se hace necesaria una revisión de las principales características de dichos espacios.

Tal como muestra el tratamiento de los jardines en la literatura latina ${ }^{9}$, estos sitios están cargados de artificio y lo ostentan explícitamente. A pesar de estar compuestos por elementos propios de la naturaleza, tales como flores, pastizales, árboles y demás, los jardines también suelen incorporar objetos propios de la creación humana como, por ejemplo, huertos, fuentes arregladas y estatuas, entre otros. Por añadidura, la plasmación de los jardines en la literatura deja ver la doble manipulación de sus ornamentos: la que necesariamente compete a la modificación de las partes constitutivas del jardín por parte del hombre para efectuar la creación de dicho ámbito (pues el ordenamiento y la disposición de todo paisaje de este tipo siempre muestra un espacio artificialmente alterado ${ }^{10}$ ) y la que, a su vez, hace el poeta que, mediante la escritura, estampa el jardín en su texto ${ }^{11}$. De hecho, como nota Wallace-Hadrill ${ }^{12}$, estos sitios han sido de gran importancia en Roma a partir del período republicano, pues además de continuar con la 'moda' de la utilización de los jardines urbanos y suburbanos como espacios de lujosa ostentación, apartados de la vida política y capaces de brindar estadías destinadas al otium y la voluptas, también se vinculan con la 'helenización' romana y la selección y apropiación mimética (aunque también crítica) de los estándares extranjeros por parte de la Urbs. Esto último se traslada también al arte, como lo prueban las tan comunes representaciones pictóricas de los jardines que, en su tendencia a emular los reales, dejan ver que "art and nature are not easily separated when art aims to be so minutely representational, and nature is so artifical" ${ }^{13}$.

El tratamiento del jardín se vuelve especialmente significativo en un texto como Fasti. Por un lado, el calendario ovidiano muestra claras vinculaciones con el discurso didáctico, tipo textual que en más de una oportunidad se ocupó del tratamiento de la tierra y la confección y el cuidado de sus bondades, tal como dejan 
ver los Georgica virgilianos y el De agri cultura de Catón, por citar solo algunos ejemplos. A su vez, dado que la configuración del jardín se erige sobre la manipulación de los elementos naturales por parte del hombre, dicha tarea no puede escaparle a la dinámica impuesta por el tiempo, con lo cual podemos decir también que a esta actividad le resulta indispensable la consulta del calendario ${ }^{14}$, asunto que no en vano constituye el principal propósito temático de los Fasti. De este modo, el escenario que aporta el jardín implica, desde ya, la idea de 'generación', pues el surgimiento de los ítems que forman parte de él apela a una instancia de permanente creación, que en este caso será tanto natural como artificiosa y, por ende, literaria.

A diferencia del jardín, cuyo desarrollo supone un proceso, el locus amoenus parece ser un 'espacio dado', recortado y suspendido en el tiempo e incapaz de alterarse. El tópico del locus amoenus que, en efecto, ha llamado ampliamente la atención de la crítica ${ }^{15}$, comprende un paisaje natural, generalmente provisto de árboles, sombra refrescante, leves brisas, algún arroyo o un lago calmo, flores y canto de pájaros ${ }^{16}$. Su imagen es la de un sitio agradable y alejado de las hostilidades de la ciudad, que puede estar habitado por agentes humanos o divinos, tanto en su estado original como metamorfoseados ${ }^{17}$. Si bien se configura como un espacio compuesto por elementos de la naturaleza cuya disposición parece recrear un paisaje que hasta puede involucrar marcas constitutivas del ámbito mediterráneo ${ }^{18}$, su misma presencia siempre supone algo de artificio ${ }^{19}$, pues el locus amoenus es ante todo un espacio ficcional y, además de erigirse como tal a través de la manipulación de sus componentes naturales por parte de los poetas, trae consigo las distintas circunstancias literarias a las que suele servir de marco, tales como el refugio del mundo exterior, la inspiración poética o la distracción erótica ${ }^{20}$.

Al tratarse de un escenario poético, consideramos que no tiene ningún sentido asumirlo como inalterable sino que también se trata de un espacio generador, transmisor de mensajes y creador de nuevos sentidos. Por ejemplo, según muestran múltiples escenas de las Metamorphoses ovidianas, dicho paraje suele prestar lugar a episodios de violencia sexual ${ }^{21} \mathrm{y}$, al mismo tiempo, exhibir el manejo poético de los elementos naturales, algunas veces como mise en abyme de la realización de la misma obra. Esto se comprueba especialmente en Fasti, cuyos diversos episodios de violaciones y raptos suelen tener como elemento común alguna variedad del locus amoenus ${ }^{22}$.

Respecto de lo antedicho, el caso de Flora se vuelve especialmente representativo: por un lado, se trata de la divinidad consagrada al dominio de los horti, cuyos elementos constitutivos, además de estar sumamente emparentados con los del locus amoenus, también contienen una connotación artificiosa. Por otro, la incidencia del 'paraje ameno' en la divinización de Flora y en el posterior ejercicio de su poder resulta fundamental, pues brinda a la divinidad el material necesario para desarrollar y ejercer sus habilidades metamórficas.

\section{FLORA Y SUS METAMORFOSIS}

\section{a) Flora transformada y su 'bortus amoenus'}

La historia de Flora en el calendario elegíaco es por demás ovidiana: se trata de una ninfa que, tras ser violada por el dios Céfiro, accede al reinado de las flores a modo de 'compensación' o 'recompensa' por haber perdido su virginidad en favor de la satisfacción de su agresor. A partir de esta 'transformación' ${ }^{23}$ la ninfa se convierte en diosa y, a medida que cuenta esta misma historia al enunciador de Fasti, adquiere el rol de magistra, condiciones que inciden en la caracterización de su relato.

El primer episodio metamórfico que involucra a Flora corresponde a su propio nombre y ya anticipa su siguiente transformación: 


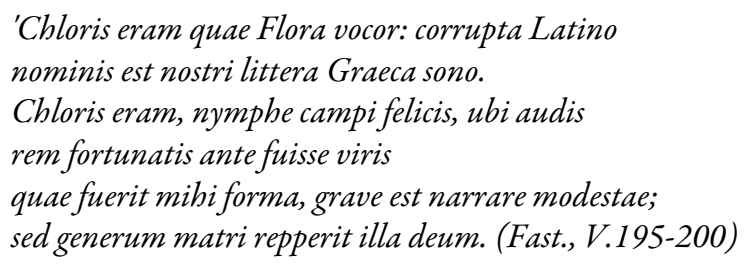

Cloris era [yo], la que ahora me llamo Flora: una letra griega de mi nombre fue corrompida por la pronunciación latina. Cloris era [yo], ninfa del campo feliz, donde escuchas que antes los hombres afortunados tenían sus asuntos. Difícil es para mí, modesta, narrar cuál fue mi belleza, pero ella encontró un yerno divino para mi madre.

El pasaje asocia la transformación de Flora con la instancia literaria que la convoca, ya que la inscribe en un elemento propio de la escritura (littera , 195-196) y explicita las instancias de narración (narrare, 199) y difusión (audis, 197) de esto que cuenta nuestra deidad modesta (199) y manipuladora de asuntos graves (199). La insistencia en la reiteración de su nombre anterior ${ }^{24}$ (Cloris eram, 195, 197) enfatiza este giro, y la identificación de su pasado con un campo feliz (197) habitado por hombres afortunados (198), alude a un espacio pretérito, próspero y de carácter pastoril ${ }^{25}$ que se vincula con la ninfa a través de la continuidad fónica que establece la aliteración inicial en [f] (Flora, 195 - felices, 197 - fortunatis, 198 - fuisse, 198 - fuerit, 199 - forma 199$)^{26}$. Este marco espacial empieza a delinear una caracterización escénica cercana a la del locus amoenus, lo cual permite vincularlo con una práctica poética metamórfica que se presenta también como un escenario en el que se cuentan historias (ubi audis, 197).

La segunda transformación convierte a la ninfa en diosa (201-206) y se sitúa en un contexto primaveral (ver erat, 201) que será consecuente con el poderío que el personaje habrá de adquirir más adelante. Aquí Céfiro atrapa a Flora en su fuga y la agrede sexualmente: la alcanza por ser fortior (202), aunque también es asociado con elementos molles en otras instancias del texto ${ }^{27}$, lo cual remite, desde el punto de vista temático, a las marcas de ambigüedad genérica propia de Fasti. Quizás sea esta última cualidad la que le permite enmendar a Céfiro su actitud (vim...emendat, 205) con una unión matrimonial que cuenta con la anuencia ${ }^{28}$ de la ninfa y que, expresada a través de la callida iunctura querella toro (206), incluye dos elementos característicos de la elegía (el primero, propio del tono de lamentación que caracteriza originalmente a este género y, el segundo, comúnmente utilizado para designar por metonimia la actividad sexual ${ }^{29}$ ). Esta transformación es llamada a compensar la violación de Flora y le otorga el imperio sobre los jardines:

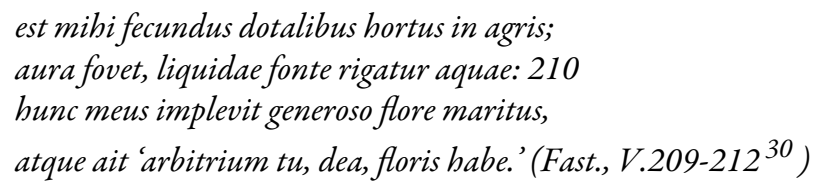

Tengo un jardín fecundo en los campos que conforman mi dote. La brisa lo acaricia, es regado por una fuente de agua clara; mi marido lo llenó de magnánimas flores y me dijo: 'ten tú, diosa, el poder sobre las flores'.

La descripción del hortus del que Flora se hace acreedora (est mibi, 209; habe, 212) se yergue sobre una tipología provista de abundante vegetación (agris, 209), aires tenues (aura, 210), flores (flore, 211; floris, 212) y fuentes de agua cristalina (liquidae fonte... aquae, 210), cuestión que parece asimilar las características de dicho escenario a las de un locus amoenus, espacio que no casualmente se inscribe inmediatamente después de un episodio de violación. A primera vista, el espacio del que Flora se adueña parece haberse generado y sustentarse naturalmente: la brisa lo refresca por sí misma (fovet, 210) y es regado espontáneamente según la acción del agua de la fuente (rigatur, 210). No obstante, esta suerte de hortus amoenus da muestras de su carácter artificial al hacer explícito su propio montaje a partir de la manipulación de sus componentes por parte de Céfiro (implevit, 211), quien da forma al sitio mediante la disposición y distribución intencional de tales elementos. Este nuevo espacio pasa a ser pertenencia de Flora y la beneficia con una suerte de 
'patrimonio' floral expresado en términos matrimoniales (dotalibus...agris, 209; meus...maritus, 211), cosa que insiste en la idea de artificio al mismo tiempo que parece 'consolidar' la unión entre dos personajes ambivalentes para otorgarle a la ahora diosa un jardín fecundus (209) sobre el que ella ejercerá su arbitrium (212), con la consiguiente posibilidad de crear. Así fue transformada Flora y así también lo fue su jardín, según oye por boca de la diosa el discipulus enunciador.

\section{b) Flora transforma y 'enseña' su hortus amoenus}

Con este nuevo poderío, la Flora transformada se convierte, también, en 'transformadora', pues adquiere el poder de manipular ella misma los componentes naturales que conforman sus dominios y puede así generar nuevos elementos para el espacio en el que impera:



Yo primera esparcí nuevas semillas por las inmensas regiones: la tierra antes era de un único color. Yo primera hice de la sangre de Terapneo una flor, y la queja permanece escrita en su hoja. Tú también tienes un nombre a través de los jardines cultivados, Narciso, desdichado, pues no eras ni uno ni otro. ¿Y qué diré acerca de Croco o Atis o el hijo de Cíniras, de cuyas heridas surgió, a través de mí, el honor?

Como vemos, ahora es Flora quien modifica los elementos naturales para dar vida a sus propias creaciones (sparsi, 221; feci, 223; perme, 228) y, al reconocerse prima (221,223), se posiciona como pionera en la materia 31 , cuestión que también la convierte en fundadora. El léxico del sintagma scripta querella (224) delinea el carácter escrito de este discurso e inscribe el mensaje de Flora en una praxis literaria vinculada a la elegía, marco estético en el que insisten los términos infelix (226) y volnere (228). No casualmente esta escritura se realiza sobre elementos propios del paisaje natural (in folio suo, 224) que, a su vez, fueron intervenidos artificialmente (cultos...per hortos , 225), de modo que se asocian con el poder generador de Flora a partir de elementos constitutivos de su propia jurisdicción y al mismo tiempo modifican dicho paisaje al asignarle nuevos 'integrantes' como las flores mencionadas. A diferencia de la uniformidad del paradigma anterior, al que se alude mediante otro ítem espacial como la tierra (unius tellus ante coloris erat, 222), las obras de Flora, igualmente señaladas a partir de componentes paisajísticos (color, 222; florem, 223), son de materia variada, novedosa y metamórfica ( nova semina ,221). Así lo muestran las distintas flores que componen esta nueva vegetación, las cuales remiten, a su vez, al mismo poema de Metamorphoses ${ }^{32}$ ovidianas, donde se narran las etiologías del jacinto (Therapneo, 223); el narciso (Narcise, 225); el azafrán (Crocon, 227); el árbol de abeto surgido tras el deceso de Atis (Attin, 227); y la anémona, originada al morir Adonis (Cinyra...creatum, 225). Al remitir a uno de los textos híbridos del poeta, Flora le pone 'sello' ovidiano a sus propias creaciones y explicita, asimismo, la heterogeneidad o mixtura de Fasti, según condensa la imagen del narciso (non alter et alter, 226) que parece postular la indefinición como una marca propia de este tipo de obras literarias. Por otra parte, al subrayar la idea de honor en relación con dicha praxis (surgit honor ,228), el texto muestra, por analogía, que esta poesía variada y heterogénea logrará consolidarse e imponerse como una opción válida, tal como sigue escuchando su discipulus a medida que transcurre su diálogo con la diosa.

En esta sintonía, la más llamativa creación de Flora es el nacimiento de Marte ${ }^{33}$ (Mars...per nostras editus artes , 229; Marsque creatus erat , 258), divinidad representante de la guerra, asunto asumido como poco 
compatible con el metro elegíaco, que es precisamente el soporte mediante el cual Flora se expresa. Esta 'obra' se gesta por pedido de Juno quien, en su afán de vengarse de Júpiter por dar vida a Minerva sin los requerimientos de su esposa, recrea un motivo típico de la epopeya ${ }^{34}$ y pide ayuda a Flora para que le conceda la posibilidad de ser madre sin involucrar a su marido. Dicha petición es concretada por Flora a través de una flor proveniente de otro espacio natural como los huertos olenios ${ }^{35}$ (Oleniis...ab arvis, 251), único brote en todo su jardín (flos dabit: est hortis unicus ille meis, 252) capaz de 'generar' a partir de elementos estériles (sterilem, 253). Esta flor singular consagra a Flora como 'autora' (auctor, 249) de una obra también sin parangón y elaborada con los elementos propios de su jurisdicción espacial. De este modo, el discipulus de Flora observa, dada la articulación de esta historia con el discurso de la diosa, que un espíritu iocosus retoma un tópico propio de un género particular (en este caso, el intercambio entre divinidades de distinto rango en tanto motivo de raigambre épica) y, por intermedio de este, puede generar un nuevo resultado que, aunque posea características puntuales (como es el caso de Marte, identificado con el género épico) adquiere significado propio al plasmarse por medio de nostras...artes (229) como las flores, desde el punto de vista temático y procedimental, o los dísticos, desde el punto de vista metapoético.

Tras ello, en agradecimiento por sus 'servicios', Marte le concede a Flora la entrada a la ciudad de Roma ('babeto / tu quoque Romulea' dixit in urbe locum', 259-260) e introduce a la diosa de los 'jardines amenos' en un ámbito citadino e institucional, superposición espacial que, además de mostrar las ambigüedades de la figura de Flora, parece consolidarla como divinidad ${ }^{36}$ al legitimar su capacidad de transformar. El ingreso de Flora a Roma es, también, literario, tal como ella misma deja entrever ante la pregunta por los orígenes de sus ludi (277), que la lleva a hablar acerca de la intervención de dos ediles ${ }^{37}$ (plebis ad aediles...Publicios, 287-288), quienes ponen una multa a los responsables de la explotación indiscriminada de tierras públicas en lugar de las privadas (285-286):

\author{
multa data est ex parte mibi, magnoque favore \\ victores ludos instituere novos; \\ parte locant clivum, qui tunc erat ardua rupes, \\ utile nunc iter est, Publiciumque vocant.' (Fast., V.291-294)
}

Me fue otorgada una parte de la multa y con gran aclamación los vencedores instituyeron nuevos juegos. En una parte ubican una cuesta que entonces era una alta pendiente; ahora es un camino útil y lo llaman Publicio.

El culto de la diosa actualiza nuevamente la idea de 'novedad' (ludos...novos, 292) a través de la intervención de los magistrados de la plebs y resalta, así, el carácter plebeyo de sus celebraciones. La cercanía que mantienen en el pentámetro 292 las palabras victores y ludos muestra, además, cierta fusión entre la victoria (elemento característico del género épico) y los juegos (propios de una literatura iocosa como la elegía ovidiana). Por otra parte, tras estos ludi tiene lugar la construcción del Clivus Publicius ${ }^{38}$, camino que conducía al templo de la diosa y que, también, surge a partir de una transformación espacial: aquello que antes suponía un espacio intransitable ( tunc erat ardua rupes, 293) es ahora un camino aprovechable (utile nunc iter est, 294). Ambos versos establecen un sistema de comparación entre pares que se pronuncian en pos del presente de enunciación y en detrimento del pasado (tunc - nunc; erat - est; ardua - utile; rupes - iter), mostrando cómo es que de algo aparentemente improductivo puede surgir una nueva y provechosa alternativa, no casualmente denominada iter, término que cobra especial sentido dado su habitual empleo como metáfora de la escritura ${ }^{39}$. La distribución del nombre de dicho camino entre el hexámetro (clivum, 293) y el pentámetro (Publicium, 294) subraya que este 'camino a seguir' es emprendido 'en dísticos', con lo cual vale decir que este nuevo iter, proveniente de un cambio de forma, es también literario, y que el modo de recorrerlo será acorde a la misma poética que lo delinea, vinculada tanto con la elegía como con la configuración de un espacio específico.

El poder metamórfico de Flora y su lazo con ciertas caracterizaciones del espacio se confirma en los versos siguientes (261-274), donde la diosa describe las distintas esferas que abarca su poder. Flora no solo se ocupa 
de teneris...coronis (261) sino que además atiende los campos sembrados y los frutos que estos dan, con lo cual opera a partir de la modificación artificial de determinados paisajes (en este caso, por intermedio de la siembra) y su acción se impone nuevamente como elemento generador (en la medida en que los resultados de estas siembras exhiben nuevos frutos). La condición para que los campos sembrados alcancen su prosperidad es que sus semillas puedan 'florecer': si bene floruerint segetes... (263); si bene floruerit vinea... (264); si bene floruerint oleae... (265). Este 'florecimiento' no es tarea sencilla sino que requiere de trabajo y esfuerzo, tal como deja ver el proceso de elaboración de vinos: vina quoque in magnis operose condita cellis / florent (269-270). Si esto no ocurre, los frutos perecerán una vez echada a perder la flor (flore semel laeso pereunt, 267), con lo cual la intervención de la diosa se torna imprescindible para que su jardín 'florezca'. Flora también da muestras de esto último y cuenta a su discipulus cómo ella ha plasmado oportunamente dicha situación ante la desatención de los dioses por parte de los hombres. Las actitudes de Flora ante tal desapego parecen describir no solo el alcance de su imperio sobre los espacios naturales sino también sobre la literatura al presentar un entramado de léxico propio del código elegíaco: además de señalar las posibilidades de expiación mediante el sacrificio de animales 'tiernos' (hostia blanda, 300) y de enfatizar su sufrimiento (manifesta doloris , 313), deja en claro que su sentir es el de la tristeza: excidit officium ${ }^{P}$ tristi $^{H}{ }^{H}$ mibi: nulla tuebar ${ }^{40}$ (315). Según remarcan las cesuras del hexámetro, tristi queda en el centro del verso y se ubica en medio del officium de la diosa sobre ella misma (mihi), lo cual subraya la 'interposición' de la tristeza en su labor. Esta negativa se extiende al accionar de la diosa, que descuida sus deberes y parece atentar contra la prosperidad de sus propias tierras (nec in pretio fertilis hortus erat, 316). Lo mismo parece hacer con las mieses y los olivos que, versos atrás, 'florecían' y, ahora, parecen 'marchitarse' (florebant olea, venti nocuere protervi: / florebant segetes, grandine laesa seges, 321-322) ${ }^{41}$. La situación logra modificarse cuando Flora es debidamente celebrada: convenere patres, et, si bene floreat annus, / numinibus nostris annua festa vovent, 327-328). Esta enmienda propone festividades de realización anual en sintonía con el 'florecimiento' del año, cuestión que no solo remite a la prosperidad de la siembra y la cosecha durante dicho período sino que parece aludir, también, al asunto del poema del calendario (nitidissimus annus, 265) ${ }^{42}$, quedando claro, entonces, que la acción de 'florecer' es pleno dominio de Flora, tanto respecto de los jardines como en lo concerniente a la poesía. En esto consiste el poder transformador de Flora, y es exactamente aquello que, a medida que la diosa habla, aprende su discipulus. Más aún, los dominios de esta deidad se manifiestan explícitamente en términos literarios en los versos que siguen:

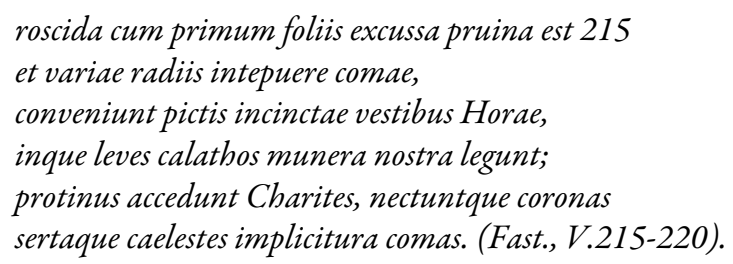

Tan pronto como la húmeda escarcha fue sacudida de las hojas y el variado follaje se ha entibiado con los rayos del sol, llegan las Horas, ceñidas en sus vestidos pintados, y recogen mis regalos en cestos livianos. Al punto se acercan las Gracias y entrelazan coronas y guirnaldas que habrán de envolver los cabellos celestes.

El primer dístico citado muestra el fin del invierno y la llegada de la primavera, época que se vincula directamente con las flores y, por ende, con nuestra deidad. A su vez, el arribo de dicha estación señala una etapa de cambio y renacimiento, con lo cual podemos entender que estos movimientos climáticos (roscida... pruina... / intepuere..., 215-216) traen consigo una instancia de creación, consecuente con la que ha sufrido Flora al pasar de ninfa a diosa y con la que ella misma ejerce al manipular los elementos de su jardín. Este marco primaveral, de hecho, es también delimitado por elementos propios del paisaje (foliis, pruina, 215; radiis, comae, 216). El léxico elegíaco que atraviesa el pasaje (leves, munera, 218) subraya nuevamente el marco estético en el que Flora inscribe su relato: este vuelve a hacer hincapié en la idea de hibridez a partir del 
motivo de la variedad ( variae...comae, 216) y de la acción de 'reunir' distintos elementos (incinctae, 217; legunt, 218; nectunt, 219; implicitura, 220). El hecho de que las encargadas de 'entrelazar' motivos sean las Gracias (Charites, 219) marca el nexo entre dicho entrelazamiento y la actividad literaria, al mismo tiempo que la mención de las Horas (Horae, 217) postula una vez más la mixtura del texto al señalar una nueva vinculación con la épica a través de las implícitas reminiscencias hesiódicas que conllevan esos personajes míticos. Asimismo, unas y otras guardan relación con la intervención de Flora en el nacimiento de Marte, pues evocan los nacimientos de las hijas de Júpiter, cuyo catálogo ${ }^{43}$ comienza con la eliminación de la figura materna tras la 'ingesta' de Metis por parte del dios y se cierra con la solitaria maternidad de Hera ${ }^{44}$. Es precisamente esta materia heterogénea la que conforma el contenido del mensaje de Flora, quien transmite al ego enunciador de Fasti una nueva forma de crear novedosas y variadas formas a partir de los elementos de su 'hortus amoenus'.

\section{FLORA Y FASTI (BIS)}

El poder transformador de la diosa se asocia, también, con su poder discursivo, dadas las diversas imágenes de 'florecimiento' que la deidad vincula con instancias creadoras $(263 ; 265 ; 264 ; 270 ; 321-322 ; 327)$ y la marca de la fragancia floral en el acto de hablar (dum loquitur, vernas efflat ab ore rosas, 194). El perfume que emanan las palabras de la diosa parece implicar que aquello que ella expresa habrá de dejar algún tipo de huella o rastro, resultado que siempre se espera de un discurso didáctico como el que, entendemos, ella pronuncia ante el enunciador de Fasti. Esta fragancia que exhala la boca de Flora conlleva, además, ecos calimaqueos ${ }^{45}$, de modo que su discurso se construye a partir de ciertas señales metaliterarias. Puede decirse entonces que la figura de Flora se impone en el poema del calendario como la magistra poética que el vates enunciador necesita para continuar con su propio carmen. En este sentido, la idoneidad de Flora para aquellos asuntos por los que se la consulta queda más que justificada, dado que, como expresan los verbos de movimiento que remiten a la ubicación de los Floralia en el calendario, la actividad de la deidad 'comienza' (incipis, 185), 'transita' (transis, 185) y, lejos de detenerse, sigue su marcha (eat, 190). Parece entenderse aquí el por qué de su relegamiento anterior (distuleram, 144), ya que, al traer a colación esta acción en el libro 5, se asocia el recorrido de la diosa con el final del libro 4 de Fasti y se ilustra, desde la misma escritura del poema del calendario, el movimiento de su carmen.

Esto mismo parece confirmar el final del episodio ${ }^{46}$, cuando Flora culmina sus lecciones:

$$
\begin{aligned}
& \text { omnia finierat }{ }^{P} \text { : tenues }{ }^{H} \text { secessit in auras, } \\
& \text { mansit odor; posses scire fuisse deam. } \\
& \text { floreat ut toto }{ }^{P} \text { carmen }{ }^{H} \text { Nasonis in aevo, } \\
& \text { sparge, precor, donis pectora nostra tuis. (Fast., V.375-378) }
\end{aligned}
$$

Todo había terminado: la diosa se alejó hacia las tiernas brisas, permaneció el perfume: podías saber que era una diosa. Para que florezca el poema de Nasón por toda la eternidad, esparce, te ruego, mi pecho con tus dones.

A diferencia de lo que señalan las primeras dos palabras del pasaje (omnia finierat, 375), no todo termina allí, ya que nuevamente permanece el perfume de la diosa (mansit odor, 376), cuya influencia dará lugar a nuevas creaciones que, esta vez, serán las del ego enunciador. Flora es invocada en función de su acción sobre los elementos de sus propios dominios espaciales ( sparge ... donis ... tuis , 378), que son los que justamente guiarán la motivación del poeta (pectora nostra, 378) y que, además, remiten nuevamente a las Gracias calimaqueas ${ }^{47}$. Aquello que el enunciador aprende se identifica con el discurso elegíaco, según resaltan las cesuras P y H de los dos hexámetros al destacar las palabras tenues (375) y carmen (377). Así, se hace alusión al 'florecimiento' de su propia obra identificable a partir de la firma o sphragis del enunciador ${ }^{48}$ (floreat...carmen 
Nasonis, 377). Efectivamente, a medida que el ego enunciador ejecuta la escritura de su calendario, da forma a su propia empresa literaria, que se 'hibridiza' a partir de la combinación de su asunto con su metro y el tono didáctico. Al apelar a los elementos propios de este jardín amoenus de Flora, esta literatura será eterna (toto...in aevo, 377) y, como tenue carmen, estará siempre en flor. De este modo, el locus amoenus que presenta este episodio, traído a cuento como una especie de 'recompensa' por el agravio sexual sufrido por Flora, en cuanto espacio artificioso brinda a la diosa elementos para ejecutar sus propias creaciones, de las que el ego enunciador 'aprenderá' a la hora de expandir su propia praxis literaria: esta será también un opus maius de alcances incontables, al igual que los colores del jardín de Flora:

$$
\begin{aligned}
& \text { saepe ego digestos volui numerare colores, } \\
& \text { nec potui: numero copia maior erat. (Fast., V.213-214) }
\end{aligned}
$$

A menudo yo quise contar los colores distribuidos. No pude. La abundancia era mayor que la cuenta.

A través del color (colores, 213), un elemento propio de las flores de su jardín, Flora parece hacer aquí un manifiesto poético a favor de la validez del soporte elegíaco para el tratamiento de asuntos variados. Así lo confirma su intención de identificar cada uno de estos elementos genéricamente diversos, tal como expresa el hexámetro o verso épico (digestos volui numerare colores, 213), para luego expresar en el pentámetro la imposibilidad de elaborar dicho catálogo (nec potui, 214) y, más aún, los motivos de esa imposibilidad (numero copia maior, 214). Las razones que no permiten contar los colores del hortus amoenus de Flora parecen explicitarse, pues, en el sintagma numero copia maior. En efecto, la primera palabra ("numero") designa el metro ${ }^{49}$ desde un punto de vista poético; a su vez, el adjetivo maior, que suele aludir, en términos literarios, a la solemnidad (y que no casualmente se sitúa en el verso elegíaco, como un señalamiento de que dicha solemnidad puede ser expresada en este metro) refiere a la variedad de contenidos implicados en el calendario ovidiano que, en este caso, se denomina copia, término que también se relaciona, como es sabido, con la 'abundancia' propia de la producción de espacios naturales como los jardines ${ }^{50}$. Esta interferencia de sentidos que confluyen en el discurso de Flora no solo exhibe una conjunción de rasgos genéricos diversos, sino también la posibilidad de plasmarlos en dísticos elegíacos. Es precisamente este discurso el que será aprendido por el mismo enunciador de Fasti, quien lo inscribe en su poema del calendario en pos de la recepción de sus propios lectores.

\section{Notas}

1 Seguimos el texto latino fijado por Alton, E.H. - Wormell, D.E.W. - Courtney, E. (eds.), P. Ovidii Nasonis Fastorum Libri Sex, Leipzig, Teubner, 2005. Nos referiremos a este trabajo mediante la sigla AWC.

2 Newlands, C. Playing with time. Ovid and the Fasti, Ithaca, 1995,104-110 y 122-123, analiza en detalle la figura de Flora y la identifica con la materia elegíaca de Fasti y su proceso de escritura. Postula que la elegía está aquí representada por un personaje femenino cuyo nombre, de origen griego, se vincula con los inicios de la elegía; de estatus lindante entre las categorías de matrona y meretrix; y diferente a la representación de la elegía que el mismo Ovidio esgrime en $A m$., III.1 pues, al igual que los mismos Fasti, Flora no toma la temática erótica como único rasgo sino que está consagrada a asuntos de peso como el calendario. La autora se detiene especialmente en el nacimiento de Marte (futuro padre de Rómulo) a partir de la acción de las flores, alumbramiento entendido como una indirecta creación del Estado romano al que se llega tras la intervención de la diosa.

3 "Elle présidait à la floraison printanière, à celle des céréales d'abord, puis à celle des arbres fruitiers et de la vigne, finalement à l'épanouissement des fleurs de pur agrément”, cf. Daremberg, M. - Saglio, E. (DAGR) Dictionnaire des antiquités grecques et romaines, Paris, 1900, s.v. Flora.

4 A pesar de esto, Fantham, E. "Ceres, Liber and Flora: Georgic and Anti-Georgic Elements in Ovid's Fasti”, PCPS 38, 1993, 50, nota que los escritores augustales han tendido a ignorar tanto a la diosa como a sus juegos, a excepción de Ovidio. También rescata el aporte de Varrón, cuyo material nos llega a partir de Plin. Nat. 18.

5 Barchiesi, A. The Poet and the Prince. Ovid and Augustan Discourse, Berkeley, Los Angeles, London, 1997, 133-140, encuentra aquí una especie de 'competencia' entre diosas en la que una deidad menor, consagrada a la materia iocosa y 
representante de la libertad espiritual y sexual, es corrida de escena por una diosa principal, digna de asuntos solemnes y promotora de la castidad, certamen que representa las distintas líneas genéricas que conviven en el texto. Asimismo, observa que esta polaridad Vesta-Flora no necesariamente es tal, puesto que la figura de la primera deidad en Fasti es tratada de formas diversas que, muchas veces, la alejan del plano de esta supuesta 'solemnidad', al mismo tiempo que el personaje de Flora no es tan irrelevante como podría creerse, lo cual, a nuestro entender, acentúa aún más esta duplicidad genérica que construye el poema.

6 Para las principales características de la poesía didáctica, cf. Volk, K. The Poetics of Latin Didactic. Lucretius, Vergil, Ovid, Manilius, Oxford, Oxford University Press, 2002; Pozzi, M. “Aproximaciones a la poesía didáctica latina”, en: Schniebs, A. (coord.), Debates en Lenguas Clásicas, Buenos Aires, Editorial de la Facultad de Filosofía y Letras de la Universidad de Buenos Aires, 2010, 105-130.

7 Cf. Newlands, C. “Ovid's Narrator in the Fasti”, Arethusa 25, 1992, 33-54; Playing with time, 105; Merli, E. Arma canant alii. Materia epica e narrazione elegiaca nei Fasti di Ovidio, Firenze, Università degli Studi di Firenze, 2000, 138; Green, G. “Docens Poeta: Development of the Interviewer's Skills in Ovid's Fasti”, Latomus 60, 2001, 603.

8 Newlands, Playing with time, 109-110, señala que Flora se vincula con el acto de escribir a partir de su capacidad de crear flores (que son una común metáfora de ornamentos estilísticos) y del tejido de guirnaldas, tarea que alude habitualmente a la creación literaria. Para la autora (con quien coincidimos), al igual que el poeta, Flora crea textos.

9 Para el tratamiento de los jardines en la literatura romana, cf. principalmente Henderson, J. The Roman Book of Gardening, Routledge, London-New York, 2004. Para algunos desarrollos puntuales de esta temática en textos específicos, cf. Gowers, E. "Vegetable love: Virgil, Columella, and garden poetry", Ramus 29, 2, 2000, 127-148; von Stackelberg, K. "Performative Space and Garden Transgressions in Tacitus' Death of Messalina”, AJPh, 130, 4, 2009, 595-624.

10 Así lo manifiesta Hunt, J. D. “Ovid in the garden”, AA Files 3, 1983, 3, cuando en su estudio acerca de la reapropiación de los espacios ovidianos por parte de los jardines renacentistas, sostiene que "the miraculous quality of Italian Renaissance gardens derived obviously from the fashion in which its natural and artifcial elements were combined”.

11 Cf. Henderson, The Roman Book of Gardening, 5; McIntyre, Written into the Landscape, 1-2.

12 Cf. Wallace-Hadrill, A. "Horti and Hellenization”, en: Cima, M. y La Rocca, E. (eds) Horti Romani: Atti del Convegno Internazionale, Roma, "L'Erma” di Bretschneider, 1998, 1-12.

13 Cf. Wallace-Hadrill, "Horti and Hellenization", 9.

14 Cf. Henderson, The Roman Book of Gardening, 8.

15 Múltiples estudios se han encargado del locus amoenus. Además de los clásicos trabajos de Curtius (Curtius, E. R. Literatura europea y edad media latina I, (trad.: Alatorre, M. F. y Alatorre, A.), México-Buenos Aires, Fondo de Cultura Económica, 1955) y Schönbeck (Schönbeck, G. Der locus amoenus von Homer bis Horaz, Heidelberg, 1962), tanto Malaspina (Malaspina, E. “Tipologia dell'inameno nella letteratura latina. Locus horridus, paesaggio eroico, paesaggio dionisicaco: una proposta di risistemazione”, Aufidus 8, 23, 1991, 7-22) como McIntyre (McIntyre, J. S. Written into the Landscape: Latin Epic and the Landmarks of Literary Reception, 2008 (consultado el 31-08-2017)), presentan completos estados de la cuestión.

16 Así enumera Curtius, Literatura europea Literatura europea y edad media latina, 280. McIntyre, Written into the Landscape, 10, considera que estos elementos constituyen la "gramática básica" del locus amoenus.

17 Cf. McIntyre, Written into the Landscape, 10.

18 McIntyre, Written into the Landscape, 12, señala que la construcción de algunos espacios propios de la literatura clásica está determinada por la geografía mediterránea y que este es el caso del locus amoenus: "Within the locus amoenus the topography of the imagination is mapped onto the "real" landscape, bounded by the experience of the reader, evoking the specificities of place, yet reorganising space as a means of suggesting sensation via the text". A su vez, Bernstein, N. W. "Locus Amoenus and Locus Horridus in Ovid's Metamorphoses", Wenshan Review of Literature and Culture 5, 1, 2011, 74, nota que la umbra de Verg., E., I.4 se hace necesaria en medio del calor propio del clima mediterráneo.

19 Cf. McIntyre, Written into the Landscape, 11.

20 En lo referente a la literatura latina, es principalmente durante el período augustal cuando el locus amoenus se fortalece como elemento metapoético, al mismo tiempo que se vincula con los pormenores del contexto político y social (cf. McIntyre, Written into the Landscape, 11).

21 Para el abordaje del locus amoenus y la violencia sexual en las Metamorphoses ovidianas, cf. principalmente Parry, H., “Ovid's Metamorphoses: Violence in a Pastoral Landscape", TAPhA 95, 1964, 268-282 y Segal, C. Landscape in Ovid's Metamorphoses: A Study in the Transformations of a Literary Symbol, Wiesbaden: F. Steiner Verlag, 1969. También cf. Hinds, S. "Landscape with Figures: Aesthetics of Place in the Metamorphoses and Its Tradition", en: Hardie, R. (ed.) The Cambridge Companion to Ovid, Cambridge: Cambridge University Press, 2006, 122-49; McIntyre, Written into the Landscape, 21-25; Bernstein, “Locus Amoenus and Locus Horridus in Ovid's Metamorphoses”, 67-98.

22 Cf. Ov., Fast., I.221-224 (Lotis y Príapo); II.153-192 (Calisto); II.313-316 (Ónfale y Fauno); II.587-588 (Yuturna y Júpiter); II.609-610 (Lara y Mercurio); II.703-708 (Sexto Tarquinio, antes de violar a Lucrecia); III.13-20 (Marte y 
Rhea Silvia); III.235-242 (donde las mujeres sabinas veneran a Marte); IV.427-430 (Proserpina); V.609-616 (Europa); VI.115-118 (Jano y Crasne); VI.327-322 (Príapo y Vesta). Para las violaciones en Fasti, cf. Richlin, A. “Reading Ovid's Rapes", en: Richlin, A. (ed.) Pornography and Representation in Greece and Rome, Oxford, Oxford University Press, 1992, 158-179 - especialmente, 169-172-); Hejduk, J. D. "Epic Rapes in the Fasti", CPh 106, 1, 2001, 20-31.

23 Para el estudio de la poética metamórfica en este pasaje desde un punto de vista métrico-estilístico, cf. Tola, E. "La celebración de Flora en los Fastos de Ovidio (V, 183-378): mito de origen y poética metamórfica”, Euphrosyne 37, 2009, 317-325

24 Esto corresponde a una falsa etimología. Se estima que el nombre Flora no posee ningún antecedente etimológico griego sino que, simplemente, deriva del término latino flos. Para este tema, cf. Porte, D. L'étiologie religieuse dans les Fastes d'Ovide, Paris, Les Belles Lettres, 1985, 239; Maltby, R. A Lexicon of Ancient Latin Etymologies, Leeds, 1991, s.v. Flora.

25 Johnson, P. J. Ovid before Exile. Art and Punishment in the Metamorphoses, Wisconsin, 2008, 43-44, marca el género pastoril como un antecedente recuperado por Ovidio, puntualmente en Met., V.

26 Cf. Brookes, I. N. Literary Commentary on the Fifth Book of Ovid's Fasti, 1992, 112, (consultado el 9-09-2017).

27 Brookes, I. N. Literary Commentary on the Fifth Book of Ovid's Fasti, 114, observa que la figura de Céfiro como agresor sexual invierte la imagen que tradicionalmente se tenía de él, que suele ser descripto como un viento propicio y amable, tal como puede verse en Fast., VI.715 (Siqua fides ventis, Zephyro date carbasa, nautae ("si [puede confiarse] en los vientos, entregad las velas a Céfiro, marineros”)). Señala también que esta 'benevolencia' es la que lo distingue de su hermano Bóreas (II.147-148): en etiam, siquis Borean horrere solebat, / gaudeat: a Zephyris mollior aura venit (“ivamos! si Bóreas solía estremeceros, disfrutad [ahora]: del Céfiro llega una brisa más suave”).

28 Fucecchi, (Fucecchi M. "L’orgoglio dei meno grandi: autocoscienza, sagacia e abilità diplomatica di alcune divinità 'minori' dei Fasti”, en: Landolfi, L. (ed.) Nunc teritur nostris area maior equis. Riflessioni sull'intertestualità ovidiana - I Fasti, Palermo, 2004, 25-46, 32) señala el "ascenso social” al que accede Flora al casarse con Céfiro, y Murgatroyd (Murgatroyd, P. Mythical and Legendary Narrative in Ovid's Fasti, Leiden, 2005, 50) marca este matrimonio como uno de los elementos de los que la diosa hace alarde. Newlands, Playing with time, 108, insiste en el estatus intermedio de Flora como matrona y meretrix.

29 Cf. Pichon, R., Index uerborum amatorium, Hildesheim-Zúrich-Nueva York, Georg Olms Verlag, 1991, $281-282$.

30 Omitimos aquí el dístico 207-208 ([vere fruor semper: semper nitidissimus annus, / arbor habet frondes, pabula semper bumus] ("Gozo de la primavera siempre; siempre está muy radiante el año. El árbol siempre tiene hojas, la tierra siempre tiene pasto”)) dado que algunos estudiosos de nuestra especialidad lo han considerado espurio (cf. AWC (eds.), P. Ovidii Nasonis Fastorum Libri Sex, 1985, 120; Nagle, B.R. Ovid. Fasti V, Bryn Mawr College, 1996, 50. Por su parte, Bömer (Bömer, F. (ed.) P. Ovidius Naso. Die Fasten, 2 vols., Heidelberg, 1957-1958); Frazer (Frazer, J.G. Publii Ovidii Nasonis Fastorum Libri Sex, London, [1929] 1989); Schilling (Schilling, R. Ovide. Les Fastes. Tomes I-II, 1993, Paris, Les Belles Lettres) y Canali (Canali, L. Ovidio. I Fasti. Introduzione e traduzione. Note di M. Fucecchi, Milano, BUR, [1998] 2016), los incluyen sin marcación alguna. Brookes (Brookes, Literary Commentary on the Fifth Book of Ovid's Fasti, 115-116) esgrime serias razones para dar crédito a la opinión de AWC.

31 Cf. Tola, "La celebración de Flora en los Fastos de Ovidio", 7. Por su parte, Citroni (Citroni, M. "Horace’s Epistle 2.1, Cicero, Varro, and the Ancient Debate about the Origins and the Development of Latin Poetry", en: Farrel, J. - Neils, D. (eds.) Augustan Poetry and the Roman Republic, 2013, 181) nota que "[a]s the heir of Archilocus in iambic verse, and of Alcaeus in lyrical poetry, Horace proclaims that he is primus: that is to say, he presents himself as an absolute initiator of these genres in the history of Latin poetry. These affirmations of priority are frequent in Augustan poets: typically, they declare that they are the initiators of their genre, and that they have at the same time brought it to a full maturity, seeing that the canonical Greek model has been equalled for the first time in Latin". Sobre estos aspectos, cf. también Deremetz, A. Le Miroir de Muses. Poétiques de la reflexivité à Rome, Villeneuve d'Ascq, 1995.

32 Para el Terapneo, cf. Ov., Met., X.162-219 y, para este epíteto, cf. Bömer, P. Ovidius Naso. Die Fasten,1958, 305; para Narciso, cf. Met., III.340-510; para Croco, cf. Met., IV.283-284 y Bömer, Ovidius Naso. Die Fasten, 306 para la identificación de la flor; para Atis, cf. Met., X.109-115 y Bömer, Ovidius Naso. Die Fasten, 306; para la anémona, cf. Met., X.708-739. También, cf. Newlands, Playing with time, 110; Hinds, "Landscape with Figures", 135-136; Tola, "La celebración de Flora en los Fastos de Ovidio", 8.

33 Cf. Newlands, Playing with time, 119.

34 Brookes, Literary Commentary on the Fifth Book of Ovid's Fasti, 169-172, nota que el pedido de auxilio a una divinidad menor por parte de otra de mayor calibre constituye un tradicional motivo épico.

35 Para el debate acerca de la posible identificación de esta flor, cf. Brookes, Literary Commentary on the Fifth Book of Ovid's Fasti, 172-177.

36 Nota Fantham, “Ceres, Liber and Flora”, 51, que Flora no es incluida en las invocaciones que abren los dos primeros libros de Georgica, cosa que, para la autora, Ovidio pretende 'reparar' en esta extensa entrevista que la diosa mantiene con el ego poético de Fasti. 
37 Se trata de Manio y Lucio Publicio Maleolo, cuya intervención es ubicada en el año 238 a.C. por Schilling, Ovide. Les Fastes II, 147.

38 El Clivus Publicius fue inaugurado en el 238 a.C. y ascendía desde el Forum Bovarium hacia el Aventino, siguiendo el mismo recorrido que hoy en día marca el llamado Clivo dei Publici (Staccioli, R. A. The Roads of the Romans, Los Angeles, Getty Publications, 2003, 17). Según Brookes, Literary Commentary on the Fifth Book of Ovid's Fasti, 137, el Clivus Publicius estaba en el Aventino y allí se habría construido el templo de Flora, con lo cual no resulta casual que la diosa indique cuál es el camino para llegar.

39 Preciso es recordar aquí la mención del camino y de la senda no hollada como metáfora de empresas literarias novedosas, recurso propio del metatexto helenístico-neotérico y ya presente en Calímaco (Aet., I.25-28).

40 Con los signos $(\mathrm{P}),(\mathrm{T})$ y $(\mathrm{H})$ designamos las cesuras pentemímeras, triemímeras y heptemímeras del hexámetro, respectivamente.

41 El accionar de la diosa en estos versos en particular y en Fast., V.315-324 recuerda la tradicional narración de la actitud de Ceres en la búsqueda de Proserpina. Fantham, "Ceres, Liber and Flora", 51-52, entiende que este pasaje retrata el modo que Ovidio encuentra para 'hacer justicia' ante el relegamiento de Flora en la literatura latina y que la asimilación de esta diosa con Ceres es un argumento llamado a abogar por su inclusión. En lo que hace a Ceres en Fasti, es comparada con Flora en V.355-360 y, además, es traída a colación en I.655-704, IV.393-620 y IV.679-712. La historia de Ceres y Proserpina también tiene lugar en Met., V.342-661. A ambos episodios y sus puntos de contacto se han dedicado, entre otros, Heinze (Heinze, R. Ovids Elegische Erzahlung, Leipzig, 1919) y Hinds (Hinds, S. The Metamorphosis of Persephone, Cambridge University Press, 1987).

42 Cf. Ov., Fast., I.1-2: Tempora cum causis Latium digesta per annum / lapsaque sub terras ortaque signa canam ("Cantaré el tiempo distribuido a lo largo del año romano junto con sus orígenes y los astros que se ponen y surgen bajo la tierra").

43 Cf. Hes., Theog., 886-929.

44 Como nota Weiden Boyd, B. "Celabitur Auctor: The Crisis of Authority and Narrative Patterning in Ovid Fasti 5", Phoenix 54, 2000, 75, el modelo que aquí sigue Ovidio es el de Hesíodo (Theog. 927), donde es Hefesto y no Ares quien nace de Hera, con lo cual la modificación que introduce Ovidio propone una resignificación de la historia original a partir del discurso de Flora. Para otros testimonios, cf. Bömer, P. Ovidius Naso. Die Fasten, 1958, 307.

45 Cf. Barchiesi, The Poet and the Prince, 134, donde se vincula este pasaje con Call., Aet., fr. VII.13ss.

46 Para un análisis métrico-estilístico de este pasaje, cf. Tola, "La celebración de Flora en los Fastos de Ovidio", 10-11.

47 Cf. Miller, J. F. “Ovid's Divine Interlocutors in the Fasti”, en Deroux, C. (ed.), Studies in Latin Literature and Roman History III, 1983, Brussels, 178-179, nota que tanto Calímaco (VII.13-14 Pf.) como Ovidio buscan aquí la exitosa permanencia y perduración de sus respectivos textos.

48 Para el juego de palabras "Naso - nose (nariz)", cf. Newlands, Playing with time, 123; Barchiesi, The Poet and the Prince, 134; Hinds, "Landscape with Figures”, 136. Para la sphragis, cf. Miller, J. F. “Callimachus and the Augustan Aethiological Elegy”, ANRW II, 30.1, 1982, 412.

49 Cf. Ov., Am., I.1-2: Arma gravi numero violentaque bella parabam / edere materia conveniente modis ("me disponía a escribir acerca de armas y guerras violentas en metro grave, ajustando el asunto al metro").

50 Para este dístico como ejemplo de multiplicidad metapoética, cf. Tola, "La celebración de Flora en los Fastos de Ovidio", 7-8. 